\title{
SUPERAÇÃO DA DORMÊNCIA E ARMAZENAMENTO DE SEMENTES DE Ornithogalum arabicum $\mathrm{L}$.
}
Cláudia Braga Dutra ${ }^{1}$, Ubirajara Russi Nunes ${ }^{2}$, Fernanda Alice Antonello Londero Backes ${ }^{2}$, Rodrigo Roso ${ }^{3}$, Tiéle Stuker Fernandes ${ }^{4}$, Eduardo José Ludwig ${ }^{3}$, Pablo Reno Da Silva Sangoi ${ }^{5}$

\footnotetext{
${ }^{1}$ Mestre em Agronomia pela Universidade de Passo Fundo. Email: c.bragadutra@ yahoo.com.br

${ }^{2}$ Professor(a) Doutor da Universidade Federal de Santa Maria - Departamento de Fitotecnia - Santa Maria, RS.

${ }^{3}$ Mestrando em Agronomia na Universidade Federal de Santa Maria - Departamento de Fitotecnia - Santa Maria, RS.

${ }^{4}$ Doutoranda em Agronomia na Universidade Federal de Santa Maria - Departamento de Fitotecnia - Santa Maria, RS.

${ }^{5}$ Graduando em Agronomia da Universidade Federal de Santa Maria - Departamento de Fitotecnia - Santa Maria, RS.
}

RESUMO: Ornithogalum arabicum L. é uma espécie exótica, conhecida popularmente como estrela - de - Belém e utilizada principalmente para o paisagismo. Suas sementes possuem germinação muito lenta e desuniforme devido à presença de dormência. Este estudo objetivou avaliar os tratamentos mais eficientes na superação da dormência e o efeito do armazenamento nas sementes de $O$. arabicum. Foram avaliados os seguintes métodos de superação da dormência: escarificação química com ácido sulfúrico por 2, 5 e 10 minutos; imersão em água aquecida por 2, 5 e 10 minutos; escarificação mecânica (sem embebição e com embebição de água destilada por 12 e 24 horas) no hilo, no hilo e extremidade oposta ao hilo e na lateral da semente, totalizando dezesseis tratamentos. As sementes foram armazenadas em temperatura ambiente durante seis meses e submetidas ao tratamento de superação de dormência mais eficaz e avaliadas pelos testes de germinação e de vigor. Adotou-se o delineamento inteiramente casualizado nos testes de superação de dormência e para o armazenamento foi utilizado um fatorial 2 × 2 (escarificação x armazenamento). Conclui-se que as sementes de $O$. arabicum apresentam dormência por tegumento duro e esta é superada com a escarificação mecânica realizada no hilo e na extremidade oposta ao hilo seguida de embebição por 12 e 24 horas. O armazenamento por seis meses supera a dormência tegumentar nas sementes.

Palavras-chave: Temperatura. Escarificação mecânica. Exótica. Germinação.

\section{OVERCOMING DORMANCY SEEDS AND STORAGE OF Ornithogalum arabicum} L.

\begin{abstract}
Ornithogalum arabicum L. is an exotic species, popularly known as Star - of -Bethlehem and used mainly for landscaping. But, the seeds have very slow germination and uneven due to the presence of dormancy. This study aimed to evaluate the most efficient treatments for overcoming dormancy and the effect of storage in seeds O. arabicum. The
\end{abstract}

Cultura Agronômica, Ilha Solteira, v.25, n.2, p.211-222, 2016 
following methods to overcome dormancy were evaluated: chemical scarification with sulfuric acid for 2, 5 and 10 minutes; immersion in water heated for 2, 5 and 10 minutes; scarification mechanical (without immersion and imbibing of distilled water for 12 to 24 hours) the hilum, the hilum and the opposite end to the hilum and the side of the seed, totaling sixteen treatments. The seeds were stored at room temperature for six months and subjected to treatment to overcome more effectively dormancy and evaluated by germination and vigor. It adopted a completely randomized design in of scarification testing and storage we used a factorial $2 \times 2$ (scarification $\times$ storage). It is concluded that $O$. arabicum seeds present dormancy for testa hard and this is overcome with mechanical scarification performed at the hilum and the opposite end to the hilum then imbibing for 12 to 24 hours. Storage for six months overcome the tegument dormancy in seeds.

Key words: Temperature. Mechanical scarification. Exotic. Germination.

\section{INTRODUÇÃO}

Ornithogalum arabicum L. é uma espécie ornamental de regiões mediterrâneas, possui, em média $45 \mathrm{~cm}$ de altura e deve ser cultivada preferencialmente com distanciamento de 15 a 20 centímetros. A espécie necessita de local ensolarado e protegido para o seu desenvolvimento. Nos meses de maio a junho, produz uma haste floral com um número de 8 a 12 flores perfumadas, com pistilos brancos e estames pretos e amarelos. É uma espécie adequada para ambientes fechados e se plantada no outono tende a florescer na primavera (HAY; BECKETT, 1991).

A qualidade fisiológica das sementes apresenta grande importância para o entendimento dos processos fisiológicos e bioquímicos envolvidos, assim como nas relações com fatores internos e externos (LUZ et al., 2014; MELO et al., 2014). Entretanto, as sementes podem apresentar qualidade fisiológica e condições ideais para germinação, mas o processo germinativo pode não ser desencadeado, devido principalmente à dormência (AZANIA et al., 2009; GAMA et al., 2011).

A dormência é a não germinação de sementes em razão de causas internas como a presença de substâncias inibidoras, embriões imaturos e tegumentos impermeáveis à água e gases (CARVALHO; NAKAGAWA, 2000). A dormência pode ser tegumentar ou exógena e embrionária ou endógena, e pode ocorrer independentemente uma da outra ou simultaneamente na mesma semente (FOWLER; BIANCHETTI, 2000). A dormência exógena é devida à impermeabilidade do tegumento a água ou gases e a endógena pode ser devida à imaturidade do embrião, ou à inibição fisiológica que o impeça de se desenvolver (SALVADOR et al., 2007).

A dormência causada por fatores inerentes ao tegumento da semente pode ser interrompida por escarificação, através da ruptura ou o enfraquecimento do tegumento (GUEDES et al., 2011). Esta é caracterizada como dormência tegumentar, em que neste caso, o tegumento da semente irá atuar como uma barreira para o andamento do processo germinativo (PEREZ, 2004). Popinigis (1985) relata que a impermeabilidade do tegumento

Cultura Agronômica, Ilha Solteira, v.25, n.2, p.211-222, 2016 
à água também é uma das causas mais comuns da dormência das sementes, principalmente em espécies leguminosas. As sementes com tegumento impermeável à água podem permanecer viáveis no solo durante longo período de tempo, constituindo o banco de sementes (PAZUCH et al., 2015).

Devido à carência de pesquisas com a espécie, o trabalho foi desenvolvido com o objetivo de identificar os tratamentos mais eficientes na superação da dormência e o efeito do armazenamento nas sementes de $O$. arabicum.

\section{MATERIAL E MÉTODOS}

O trabalho foi conduzido no Laboratório Didático e de Pesquisas em Sementes do Departamento de Fitotecnia, da Universidade Federal de Santa Maria, em Santa Maria - RS, no período de abril a setembro de 2013. As sementes de Ornithogalum arabicum foram coletadas de uma população de plantas cultivadas na área experimental da UFSM, beneficiadas manualmente, e realizados os seguintes testes:

Massa de mil sementes: foram utilizadas oito repetições de 100 sementes, pesadas em balança de $0,001 \mathrm{~g}$, e após calculada a variância, o desvio padrão e o coeficiente de variação dos valores obtidos das pesagens conforme as Regras para Análise de Sementes (BRASIL, 2009).

Grau de umidade das sementes: utilizou-se o método da estufa a $105 \pm 3^{\circ} \mathrm{C}$ por 24 horas, sendo a porcentagem de água calculada com base na relação entre o peso úmido e o seco, utilizando-se estufa e balança analítica com precisão de 0,001g, conforme Brasil (2009).

Métodos de superação da dormência:

a) Escarificação química: foram separadas amostras de 200 sementes e imersas em 20 $\mathrm{mL}$ de ácido sulfúrico concentrado em Becker de $100 \mathrm{~mL}$ e constantemente revolvidas com um bastão de vidro, objetivando-se uniformizar a ação abrasiva do ácido. Decorridos os períodos pré-estabelecidos de 2, 5 e 10 minutos, as sementes foram lavadas em água corrente, por 10 minutos, para que os resíduos do ácido fossem totalmente retirados.

b) Imersão em água aquecida: as sementes foram previamente separadas e colocadas em imersão durante os tempos de 2, 5 e 10 minutos em Becker com água aquecida até $100^{\circ}$ $\mathrm{C}$, com o auxílio de um ebulidor e para a verificação da temperatura com o uso de um termômetro.

c) Escarificação mecânica: foram utilizadas três metodologias para a escarificação mecânica das sementes: 1) escarificação no hilo da semente: realizada com lixa d'água número 180, onde foi feita uma fricção de forma manual durante aproximadamente 3 minutos. Partes dessas sementes foram imersas em água destilada por 12 e 24 horas; 2) escarificação no hilo e na extremidade oposta ao hilo: as sementes foram escarificadas em lixa d'água número 180, com uma fricção de aproximadamente 3 minutos nas duas

Cultura Agronômica, Ilha Solteira, v.25, n.2, p.211-222, 2016 
extremidades da semente; 3) escarificação na lateral da semente: as sementes foram escarificadas, conforme descrito anteriormente, apenas na lateral da semente.

Na Tabela 1 estão representados os testes aplicados para a superação de dormência de O. arabicum. Após a aplicação dos métodos para superar a dormência as sementes foram submetidas ao teste de germinação.

Tabela 1. Tratamentos aplicados para a superação da dormência das sementes de Ornithogalum arabicum.

\begin{tabular}{ll}
\hline & \\
\hline T1 & Testemunha sem embebição \\
T2 & Imersão em ácido sulfúrico por 2 minutos \\
T3 & Imersão em ácido sulfúrico por 5 minutos \\
T4 & Imersão em ácido sulfúrico por 10 minutos \\
T5 & Imersão em água à $100^{\circ}$ C por 2 minutos \\
T6 & Imersão em água à $100^{\circ}$ C por 5 minutos \\
T7 & Imersão em água à $100^{\circ}$ C por 10 minutos \\
T8 & Escarificação mecânica no hilo sem embebição \\
T9 & Escarificação mecânica no hilo com embebição de 12 horas \\
T10 & Escarificação mecânica no hilo com embebição de 24 horas \\
T11 & Escarificação mecânica no hilo e na extremidade oposta ao hilo sem embebição \\
T12 & Escarificação mecânica no hilo e na extremidade oposta ao hilo com embebição de \\
& 12 horas \\
T13 & Escarificação mecânica no hilo e na extremidade oposta ao hilo com embebição de \\
T14 & Escarificação mecânica na lateral da semente sem embebição \\
T15 & Escarificação mecânica na lateral da semente com embebição de 12 horas \\
T16 & Escarificação mecânica na lateral da semente com embebição de 24 horas \\
\hline
\end{tabular}

Teste de germinação das sementes: o teste de germinação foi realizado pelo método do rolo de papel, que consistiu no umedecimento do papel germiteste com água destilada em quantidade equivalente a 2,5 vezes a massa do papel não hidratado. As sementes foram distribuídas sobre duas folhas e cobertas com outra folha umedecida. Foram feitas 8 repetições de 25 sementes, e após a montagem, os rolos de papel foram colocados em sacos de plástico, para manter a umidade, na posição vertical, e em temperatura de $25^{\circ} \mathrm{C}$ com fotoperíodo de $12 \mathrm{~h}$ em B.O.D. (Biochemical Oxigen Demand).

Segundo as normas das Regras para Análise de Sementes (RAS), as avaliações de germinação podem apresentar diferenças entre a primeira e segunda contagem, conforme as espécies utilizadas. Porém, a espécie utilizada não possui nenhum relato na RAS, assim optou-se por elaborar uma metodologia para avaliar os testes de germinação. Do ponto de vista fisiológico, a germinação restringe-se à protrusão da raiz primária, enquanto o desenvolvimento subsequente é considerado pós-germinativo (BEWLEY; BLACK, 1994). Assim, na primeira e segunda contagem foi avaliado o número de sementes em que ocorreu a protrusão da radícula. Também foi avaliado o número de sementes duras e mortas. As 
contagens foram realizadas aos $4^{\circ}$ e $8^{\circ}$ dias após a semeadura. A primeira contagem foi considerada como indicativo de vigor e a contagem final ou segunda contagem como indicativo da viabilidade das sementes (MARCOS FILHO, 2015).

Amostras de sementes sem tratamentos para superação da dormência foram armazenadas em sacos de papel tipo "kraft" em temperatura ambiente (condição de laboratório) durante seis meses. Após o armazenamento, em parte dessas sementes foi realizada a escarificação mecânica no hilo e na extremidade oposta ao hilo com embebição de 12 horas e avaliadas pelos testes de germinação e de vigor, conforme descrito anteriormente.

Foi utilizado o delineamento inteiramente casualizado, com oito repetições para ambos os experimentos. Para os dados de armazenamento foi utilizado um esquema fatorial 2 x 2 (escarificação x armazenamento). Os dados foram submetidos à análise de variância e as médias comparadas, utilizando-se teste de Scott-Knott, adotando-se o nível de $5 \%$ de probabilidade de erro.

\section{RESULTADOS E DISCUSSÃO}

Os teores de água encontrados nas sementes de $O$. arabicum foram de $12,3 \%$, e a massa de mil sementes foi de 19,38 g, no início da montagem do experimento.

Verifica-se na Tabela 2, que os valores mais elevados de vigor (primeira contagem) e germinação foram obtidos nos tratamentos com escarificação mecânica no hilo e na extremidade oposta ao hilo com imersão de 12 horas (T12) e escarificação mecânica no hilo e na extremidade oposta ao hilo com imersão de 24 horas (T13) com 84\%, quando comparados às outras metodologias utilizadas. Além disso, apresentaram apenas 13\% de sementes duras, o que demonstra que esses tratamentos foram eficientes na superação da dormência das sementes de $O$. arabicum.

Estes resultados foram semelhantes aos obtidos por Borges et al. (1980) que utilizaram como metodologia o desponte na extremidade oposta ao embrião de sementes de Enterolobium contortisiliquum Vell. Santarém e Aquila (1995) também observaram que um corte na testa da semente na região oposta ao eixo embrionário proporcionou maiores percentuais de germinação em sementes de Senna macranthera DC. Smiderle e Sousa (2003) constataram em seu trabalho que a técnica de escarificação mecânica com lixa mostrou-se mais eficiente para a germinação de sementes de Bowdichia virgilioides Kunth, quando comparadas às técnicas de escarificação química com ácido sulfúrico por 10 minutos. Também, Alves et al. (2007) em testes de germinação com sementes de Caesalpinia pyramidalis Tul., relatam que a escarificação com lixa d’água promoveu maior velocidade de germinação quando comparada com outros tratamentos.

Os tratamentos em que foi realizada a escarificação mecânica no hilo (sem e com embebição por 12 e 24 h) (T8, T9 e T10), e na extremidade oposta ao hilo sem embebição (T11), apresentaram valores intermediários de vigor e germinação, sendo inferiores estatisticamente aos tratamentos com escarificação mecânica no hilo e na extremidade

Cultura Agronômica, Ilha Solteira, v.25, n.2, p.211-222, 2016 
oposta ao hilo com embebição de 12 e 24 horas (T12 e T13) (Tabela 2). Já os tratamentos com escarificação mecânica na lateral da semente sem embebição e com embebição de 12 e 24 horas (T14, T15 e T16) não se mostraram eficientes na superação da dormência, resultando em elevada quantidade de sementes duras (30 e $36 \%$ ).

O uso da escarificação mecânica nas sementes de O. arabicum, assim como relatado por Lopes et al. (2004) em sementes de Ormosia arborea (Vell.) Harms, mostrou resultados positivos para a germinação uma vez que promoveu a entrada de água na semente facilitando o processo germinativo. Em trabalhos realizados em Acacia mearnsii Willd obtiveram-se as maiores porcentagens de germinação na primeira contagem, quando as sementes foram submetidas à escarificação mecânica por 15 segundos (ROVERSI et al., 2002). Processo, que segundo Frank e Baseggio (1998) atribuem ao fato de que a escarificação mecânica provoca fissuras no tegumento das sementes, proporcionando aumento de permeabilidade e permitindo a embebição e aceleração do início do processo germinativo.

Tabela 2. Porcentagem de vigor, germinação, sementes mortas e duras de Ornithogalum arabicum $\mathrm{L}$.

\begin{tabular}{ccccc}
\hline Tratamentos & Vigor $(\%)^{2}$ & Germinação $(\%)^{2}$ & $\begin{array}{c}\text { Sementes } \\
\text { Mortas }(\%)^{2}\end{array}$ & $\begin{array}{c}\text { Sementes } \\
\text { Duras }(\%)^{2}\end{array}$ \\
\hline T1 & $1,2 \mathrm{f}^{1}$ & $1,2 \mathrm{f}$ & $0,0 \mathrm{c}$ & $98,7 \mathrm{a}$ \\
T2 & $7,0 \mathrm{e}$ & $18,5 \mathrm{e}$ & $19,0 \mathrm{a}$ & $62,5 \mathrm{c}$ \\
T3 & $16,5 \mathrm{~d}$ & $16,5 \mathrm{e}$ & $17,0 \mathrm{~b}$ & $66,7 \mathrm{c}$ \\
T4 & $35,0 \mathrm{c}$ & $35,0 \mathrm{~d}$ & $16,0 \mathrm{~b}$ & $49,3 \mathrm{~d}$ \\
T5 & $0,0 \mathrm{f}$ & $0,5 \mathrm{f}$ & $0,0 \mathrm{c}$ & $95,2 \mathrm{~b}$ \\
T6 & $0,0 \mathrm{f}$ & $1,0 \mathrm{f}$ & $0,0 \mathrm{c}$ & $94,1 \mathrm{~b}$ \\
T7 & $0,5 \mathrm{f}$ & $0,5 \mathrm{f}$ & $0,0 \mathrm{c}$ & $98,6 \mathrm{a}$ \\
T8 & $40,5 \mathrm{c}$ & $58,0 \mathrm{c}$ & $0,0 \mathrm{c}$ & $36,5 \mathrm{e}$ \\
T9 & $65,5 \mathrm{~b}$ & $69,0 \mathrm{~b}$ & $0,0 \mathrm{c}$ & $29,5 \mathrm{e}$ \\
T10 & $70,5 \mathrm{~b}$ & $72,0 \mathrm{~b}$ & $0,0 \mathrm{c}$ & $26,8 \mathrm{e}$ \\
T11 & $71,0 \mathrm{~b}$ & $75,0 \mathrm{~b}$ & $0,0 \mathrm{c}$ & $22,0 \mathrm{f}$ \\
T12 & $84,0 \mathrm{a}$ & $84,0 \mathrm{a}$ & $0,0 \mathrm{c}$ & $13,7 \mathrm{~g}$ \\
T13 & $84,0 \mathrm{a}$ & $84,0 \mathrm{a}$ & $0,0 \mathrm{c}$ & $13,6 \mathrm{~g}$ \\
T14 & $6,5 \mathrm{e}$ & $67,0 \mathrm{~b}$ & $0,0 \mathrm{c}$ & $30,8 \mathrm{e}$ \\
T15 & $22,0 \mathrm{~d}$ & $57,0 \mathrm{c}$ & $0,0 \mathrm{c}$ & $36,2 \mathrm{e}$ \\
T16 & $21,0 \mathrm{~d}$ & $62,5 \mathrm{c}$ & $0,0 \mathrm{c}$ & $34,8 \mathrm{e}$ \\
\hline CV $(\%)^{3}$ & 19,3 & 15,2 & 31,8 & 11,6 \\
\hline
\end{tabular}

${ }^{1}$ Médias seguidas pela mesma letra na coluna não diferem entre si, ao nível de 5\% de probabilidade, pelo Teste de Scott-Knott. ${ }^{2}$ Percentuais transformados por graus (arcosen $\sqrt{ }(x / 100) .{ }^{3}$ Coeficiente de variação percentual.

Trabalhos realizados por Alves et al. (2004) indicam que as sementes de Bauhinia divaricata L. apresentaram vigor mais alto na primeira contagem quando utilizado o desponte na região oposta à micrópila e escarificação com lixa. O mesmo foi relatado por Santos et al (2004), com sementes de Sterculia foetida L. onde verificaram maiores porcentagens de germinação na primeira contagem, quando foram escarificadas nos dois 
lados, sem embebição, seguidas por aquelas submetidas à escarificação mecânica em um lado com embebição.

Os tratamentos com imersão das sementes em ácido sulfúrico por 2, 5 e 10 minutos (T2, T3, T4) não foram efetivos para o vigor e germinação (Tabela 2), além de causar a mortalidade das sementes, entre 16 e 19\%, e sementes duras variando de 49 a 66\%, mostrando-se ineficientes na superação da dormência das sementes de O. arabicum. Esses resultados indicam que a exposição de sementes ao ácido sulfúrico, em diferentes tempos, pode proporcionar resposta negativa às características específicas de algumas espécies (GROTH, 2001). O ácido sulfúrico pode promover a deterioração da camada impermeável das sementes e a concentração do produto químico pode causar a intoxicação e morte do embrião (AZANIA et al., 2003). Esse fato pode explicar a baixa germinação nas sementes de O. arabicum e os maiores valores de sementes mortas em todos os tratamentos utilizados (Tabela 2). Além desses, Seneme et al. (2012) analisando sementes de Peltophorum dubium T., verificaram que o tempo de imersão das sementes em ácido sulfúrico durante 6 minutos não foi eficiente para superar a dormência das sementes, além de aumentar a quantidade de sementes mortas.

Entretanto, Teixeira et al. (2011) relataram que o tratamento com ácido sulfúrico mostrou maior eficiência na superação de dormência de Omosia arborea Vell., provavelmente porque promoveu uma ruptura, total ou parcial, do tegumento, facilitando a entrada de água e desencadeando o processo de germinação. Este fato foi relatado por Bewley e Black (1994) e verificado por outros pesquisadores com sementes de Mimosa caesalpiniaefolia Benth. (BRUNO et al., 2001; GARCIA et al., 2002), Bowdichia virgilioides Kunth. (SMIDERLE; SOUZA, 2003), Bauhinia monandra Britt. (ALVES et al., 2004) e de Ormosia arborea Vell (LOPES et al., 2004), que apresentam tegumento impermeável, e que o tratamento com ácido sulfúrico proporcionou resultados eficientes na superação desse tipo de dormência.

A imersão das sementes em água à temperatura de $100^{\circ} \mathrm{C}(\mathrm{T} 5, \mathrm{~T} 6$ e T7) resultou em praticamente ausência de vigor e germinação, com elevada taxa de sementes duras, entre 94 a 98\% (Tabela 2), não se mostrando eficiente na superação da dormência.

Esses resultados corroboram com os relatados por Costa et al. (2013), em que a imersão das sementes de Bauhinia forficata $\mathrm{L}$. em água aquecida a $80^{\circ} \mathrm{C}$ durante 2 e 5 minutos não foi eficiente para superação da dormência das sementes, obtendo baixa porcentagem de germinação e valores nulos de emergência. Baixas porcentagens de germinação e emergência obtidas com as sementes de Bauhinia divaricata L. imersas em água quente a $80^{\circ} \mathrm{C}$ também podem indicar provável ocorrência de algum tipo de dano fisiológico na estrutura interna das sementes, em que a temperatura elevada possivelmente causou a morte do embrião das sementes (ALVES et al., 2004). Resultados semelhantes foram observados nas sementes de $O$. arabicum, pois a germinação foi praticamente nula nos diferentes tempos de imersão em água a $100^{\circ} \mathrm{C}$. No entanto, esses resultados podem estar atrelados ao fato dos tratamentos não apresentarem eficiência na superação da

Cultura Agronômica, Ilha Solteira, v.25, n.2, p.211-222, 2016 
dormência sementes, sendo as temperaturas ou o tempo de exposição aos tratamentos em excesso ou insuficiente, no qual contribuiu para aumentar a porcentagem de sementes duras.

O uso da água aquecida como tratamento para a superação de dormência resulta na remoção de ceras e no enfraquecimento do tegumento (ZAIDAN; BARBEDO, 2004), proporcionando o surgimento de fissuras que permitem a absorção de água para desencadear o processo germinativo (PACHECO; MATOS, 2009). Nesse sentido, Soares et al. (2011) utilizando a imersão em água quente a $80^{\circ} \mathrm{C}$ durante 10 minutos, encontraram bons resultados de germinação, pois a água aquecida promoveu o enfraquecimento dos tecidos e acelerou as reações fisiológicas do tegumento das sementes, o que favoreceu a absorção de água, trocas gasosas e a germinação. No entanto, deve-se tomar cuidado quanto à temperatura e ao tempo de exposição destes tratamentos, para que as lesões causadas pelo aquecimento da água não provoquem a redução do vigor, mortalidade das sementes e a elevação das taxas de infecção por fungos (SOARES et al., 2011).

Nas sementes de O. arabicum armazenadas por 6 meses e submetidas a escarificação mecânica no hilo e na extremidade oposta ao hilo com embebição de 12 horas, os valores de vigor e germinação foram elevados, 82 e $88 \%$ respectivamente, de forma semelhante aos resultados obtidos antes do armazenamento, com $84 \%$ de vigor e germinação (Tabela 3 ).

Tabela 3. Vigor e germinação de $O$. arabicum, sem e com escarificação mecânica das sementes, antes e após o armazenamento.

\begin{tabular}{|c|c|c|}
\hline \multirow{3}{*}{ Escarificação } & \multicolumn{2}{|c|}{ Armazenamento } \\
\hline & Inicial & Seis meses \\
\hline & \multicolumn{2}{|c|}{ Vigor $^{2}$} \\
\hline Sem & $1 \mathrm{Bb}^{1}$ & $11 \mathrm{Ab}$ \\
\hline Com & $84 \mathrm{Aa}$ & $82 \mathrm{Aa}$ \\
\hline \multirow[t]{2}{*}{$\mathrm{CV}(\%)^{3}$} & & \\
\hline & \multicolumn{2}{|c|}{ Germinação $^{2}$} \\
\hline Sem & $1 \mathrm{Bb}$ & $92 \mathrm{Aa}$ \\
\hline Com & $84 \mathrm{Aa}$ & $88 \mathrm{Aa}$ \\
\hline
\end{tabular}

${ }^{1}$ Médias seguidas pela mesma letra minúscula na coluna e maiúscula na linha não diferem entre si, ao nível de $5 \%$ de probabilidade, pelo teste de Scott-Knott. ${ }^{2}$ Percentuais transformados por graus $(\operatorname{arcosen} \sqrt{ }(\mathrm{x} / 100)$. ${ }^{3}$ Coeficiente de variação percentual.

Entretanto, seis meses após o armazenamento, nas sementes sem escarificação, não houve expressão do vigor (11\%), mas houve elevada germinação (92\%), evidenciando que o armazenamento superou a dormência tegumentar das sementes de O. arabicum quando comparado aos resultados obtidos antes do armazenamento (Tabela 3). Isto evidencia que o vigor é mais sensível que a germinação, para definir o desempenho das sementes frente ao armazenamento (COELHO et al., 2010).

Em trabalhos realizados por Santarém e Aquila (1995) com sementes de Senna macranthera DC, o armazenamento por dois anos favoreceu a germinação devido ao desgaste no tegumento provocado pela dessecação. Em Mimosa bimucronata DC também 
foi observado que, além da escarificação, o armazenamento por um ano favoreceu a germinação, o que poderia ser o responsável pelo aumento da permeabilidade do tegumento, reduzindo o número de sementes dormentes (FERREIRA et al., 1992). Além disso, em sementes de mamão do grupo formosa, foi observado que durante o armazenamento as sementes mostraram maiores valores de germinação no terceiro mês, seguidos do período inicial e do sexto mês de armazenamento (MARTINS et al., 2005). Resultados semelhantes também foram encontrados por Aroucha et al. (2003) e Viggiano (1999), no qual as sementes mamão apresentaram maiores valores de germinação após quatro meses de armazenamento.

\section{CONCLUSÃO}

As sementes de Ornithogalum arabicum apresentam dormência por impermeabilidade do tegumento, sendo superada com a escarificação mecânica realizada no hilo e na extremidade oposta ao hilo, seguida de embebição por 12 e 24 horas.

$\mathrm{O}$ armazenamento por seis meses supera a dormência tegumentar das sementes de $O$. arabicum.

\section{REFERÊNCIAS BIBLIOGRÁFICAS}

ALVES, A. U.; DORNELAS, C. S. M.; BRUNO, R. L. A.; ANDRADE, L. A.; ALVES, E. U.; Superação da dormência em sementes de Bauhinia divaricata L. Acta Botânica Brasilica, São Paulo, v. 18, n. 4, p.871-879, 2004.

AlveS, E. U.; BRUnO, R. L. A; AlveS, A. U.; AlveS, A. U.; CARDOSO, E. A.; GALINDO, E. A.; JÚNIOR, J. M. B. Germinação e biometria de frutos e sementes de Bauhinia divaricata L. (Leguminosae). Sttientibus Série Ciências Biológicas, Feira de Santana, v. 7, n. 3, p.193-198, 2007.

AROUCHA, E. M. M.; SILVA, R. F.; OLIVEIRA, J. G.; BALBINOT, E. Avaliação da germinação e vigor das sementes se mamão (Carica papaya L.) após armazenamento dos frutos e sementes. In: PAPAYA BRASIL: QUALIDADE DO MAMÃO PARA O MERCADO INTERNO, 1., 2003, Vitória. Resumos... Vitória: INCAPER, 2003. 728 p.

ÁVILA, P. F. V.; VILLELA, F. A.; ÁVILA, M. S. Teste de envelhecimento acelerado para avaliação do potencial fisiológico de sementes de rabanete. Revista Brasileira de Sementes, Brasília, v. 28, n. 3, p.52-58, 2006.

AZANiA, A. A. P.; AZANIA, C. A. M.; PAVANI, M. C. M. D.; CUNHA, M. C. S. Métodos de superação de dormência em sementes de Ipomoea e Merremia. Planta Daninha, Viçosa, v. 21, n. 2, p.203-209, 2003.

AZANIA, C. A. M.; MARQUES, R. P.; AZANIA, A. A. P. M.; ROLIM, J. C. Superação da dormência de sementes de corda-de-viola (Ipomoea quamoclit e I. hederifolia). Planta Daninha, Viçosa, v. 27, n. 1, p.23-27, 2009.

Cultura Agronômica, Ilha Solteira, v.25, n.2, p.211-222, 2016 
BEWLEY, J. D.; BLACK, M. Seeds: Physiology of development and germination. 2. ed. New York: Plenum Press, 1994. 445 p.

BORGES, E. E. L.; BORGES, R. C. G.; TELES, F. F. F. Avaliação da maturação e dormência de sementes de orelha-de-negro. Revista Brasileira de Sementes, Brasília, v. 2, n. 2, p.29-32, 1980.

BRASIL. Ministério da Agricultura, Pecuária e Abastecimento. Secretaria de Defesa Agropecuária. Regras para análise de sementes, Brasília, 2009. 399 p.

BRUNO, R. L. A.; AlVES E. U.; OlIVEIRA, A. P.; PAUlA, R. C. Tratamentos prégerminativos para superar a dormência de sementes de Mimosa caesalpiniaefolia Benth. Revista Brasileira de Sementes, Brasília, v. 23, n. 2, p.136-143, 2001.

CARVALHO, N. M.; NAKAGAWA, J. Sementes: ciência, tecnologia e produção. 4. ed. Jaboticabal: Funep, 2000. 588 p.

COElho, D. L. M.; AgOstini, E. A. T.; GuABERTO, L. M.; NETO, N. B. M.; CUSTÓDIO, C. C. Estresse hídrico com diferentes osmóticos em sementes de feijão e expressão diferencial de proteínas durante a germinação. Acta Scientiarum Agronomy, Maringá, v. 32, n. 3, p.491-499, 2010.

COSTA, E. S.; NETO, A. L. S.; COSTA, R. N.; SILVA, J. V.; SOUZA, A. A.; SANTOS, V. R. Dormência de sementes e efeito da temperatura na germinação de sementes de mororó. Revista Brasileira de Ciências Agrárias, Recife, v. 56, n. 1, p.19-24, 2013.

FERREIRA, A. G.; LIPP JOK, H.; HEUSER, E. D. Efeitos da escarificação sobre a germinação e do pH sobre o crescimento de Acacia bonariensis Gill e Mimosa bimucronata (DC). Revista Brasileira de Fisiologia Vegetal, Londrina, v. 4, n. 1, p.63-65, 1992.

FOWLER, J. A. P.; BIANCHETTI, A. Dormência em sementes florestais. Colombo: EMBRAPA-Florestas, 2000. 28 p. (Documento 40)

FRANKE, L. B; BASEGGIO, J. Superação da dormência em sementes de Desmodium incamum DC. e Lathyrus nervosus Lam. Revista Brasileira de Sementes, Brasília, v. 20, n. 2, p.420-424, 1998.

GAMA, J. S. M.; ALVES, E. U.; BRUNO, R. L. A.; JUNIOR, L. R. P.; MONTE, D. M. O Superação de dormência em sementes de Centrosema plumieri Benth. Revista Brasileira de Sementes, Brasília, v. 33, n. 4, p.643-651, 2011.

GARCIA, J.; DUARTE, J. B.; FRASSETO, E. G. Superação de dormência em sementes de sansão-do-campo (Mimosa caesalpiniaefolia L.). Pesquisa Agropecuária Tropical, Goiânia, v. 32, n. 1, p.29-31, 2002.

GUEDES, R. S.; ALVES, E. U.; VIANA, J. S.; GONÇALVES, E. P.; SANTOS, S. R. N.; COSTA, E. G. Tratamentos pré-germinativos e temperatura para a germinação de sementes de Apeiba tibourbou Aubl. Revista Brasileira de Sementes, Brasília, v. 33, n. 1, p.131-140, 2011.

Cultura Agronômica, Ilha Solteira, v.25, n.2, p.211-222, 2016 
GROTH, D. Caracterização morfológica de sementes de espécies invasoras da família Convolvulaceae Juss. Revista Brasileira Sementes, Brasília, v. 23, n. 2, p.01-13, 2001.

HAY, R.; BECKETT, K. A. Encyclopede des Fleur et Palntes de Jardin. Ed. Selectionch. Reader's Digest. 3. ed. Bologna: Sélection du Reader's Digest, 1991. 831 p.

LOPES, J. C.; DIAS, P. C.; MACEDO, C. M. P. Tratamentos de dormência de sementes de Ormosia arborea (Vell.) Harms. Revista Brasil Florestal, Brasília, v. 80, p.25-35, 2004.

LUZ, F. N.; YAMASHITA, O. M.; FERRARESI, D. A.; CARVALHO, M. A. C.; CAMPOS, O. R.; KOGA, P. S.; MASSAROTO, J. A. Interferência de luz, temperatura, profundidade de semeadura e palha na germinação e emergência de Murdannia nidiflora. Comunicata Scientiae, Bom Jesus, v. 5, n. 1, p.26-33, 2014.

MARCOS FILHO, J. Fisiologia de sementes de plantas cultivadas. Londrina: ABRATES, 2015. $659 \mathrm{p}$.

MARTINS, G. N.; SILVA, R. F.; ARAÚJO, E. F.; PEREIRA, M. G.; VIEIRA, H. D.; VIANA, A. P. Influência do tipo de fruto, peso específico das sementes e período de armazenamento na qualidade fisiológica de sementes de mamão do grupo formosa. Revista Brasileira de Sementes, Brasília, v. 27, n. 2, p.12-17, 2005.

MELO, P. R. B.; OLIVEIRA, J. A.; GUIMARÃES, R. M.; PEREIRA, C. E.; PINTO, J. E. B. P. Germinação de aquênios de Lychnophora pinaster em função de estádios de maturação, temperatura e luz. Científica, Jaboticabal, v. 42, n. 4, p.404-410, 2014.

PACHECO, M. V; MATOS, V. P. Métodos para a superação de dormência tegumentar em sementes de Apeiba tibourbou Aubl. Revista Brasileira de Ciências Agrárias, Recife, v. 4, n. 1, p.62-66, 2009.

PAZUCH, D.; TREZZI, M. M.; DIESEL, F.; BARANCELLI, M. V. J.; BATISTEL, S. C.; PASINI, R. Superação da dormência em sementes de três espécies de Ipomoea. Ciência Rural, Santa Maria, v. 45, n. 2, p.192-199, 2015.

PEREZ, S. C. J. G. A. Envoltórios. In: FERREIRA, A. G.; BORGHETTI, F. (orgs). Germinação: do básico ao aplicado. Porto Alegre: Artmed, 2004. cap. 7, p. 125-134.

POPINIGIS, F. Fisiologia de sementes. 2. ed. Brasília: AGIPLAN, 1985. 289 p.

ROVERSI, T.; MATTEI, V. L.; SILVEIRA JÚNIOR, P.; FALCK, G. L. Superação de dormência em sementes de acácia negra (Acacia mearnsii Willd.). Revista Brasileira Agrociência, Pelotas, v. 8, n. 2, p.161-163, 2002.

SALVADOR, F. L.; VICTÓRIA FILHO, R.; ALVES, A. S. R.; SIMONI, F.; SAN MARTIN, H. A. M. Efeito da luz e da quebra de dormência na germinação de sementes de espécies de plantas daninhas. Planta Daninha, Viçosa, v. 25, n. 2, p.303-308, 2007.

SANTARÉM, E. R.; AQUILA, M. E. A. Influência de métodos de superação de dormência e do armazenamento na germinação de sementes de Senna macranthera (Colladon) Irwin \& Barneby (Leguminosae). Revista Brasileira de Sementes, Brasília, v.17, n. 2, p.205-209, 1995.

Cultura Agronômica, Ilha Solteira, v.25, n.2, p.211-222, 2016 
SANTOS, T. O.; MORAIS, T. G. O.; MATOS, V. P. Escarificação mecânica em sementes de chicha (Sterculia foetida L.). Revista Árvore, Viçosa, v. 28, n. 1, p.01-06, 2004.

SENEME, A. M.; POSSAMAI, E.; VANZOLINE, S.; MARTINS, C. C. Germinação, qualidade sanitária e armazenamento de sementes de canafístula (Peltophorum dubium). Revista Árvore, Viçosa, v. 36, n. 1, p.01-06, 2012.

SMIDERLE, O. J.; SOUSA, R. C. P. Dormência em sementes de paricarana (Bowdichia virgilioides Kunth - FABACEAE - PAPILIONIDAE). Revista Brasileira de Sementes, Brasília, v. 25, n. 2, p.48- 52, 2003.

SOARES, J. B. C.; SILVA, C. P.; GUERRA, D. G. F.; ARUEIRA, L. J. M. Superação da dormência em sementes de Desmodium tortuosum. Agropecuária Científica no SemiÁrido, Patos, v. 7, n. 4, p.05-08, 2011.

TEIXEIRA, W. F.; FAGAN, E. B.; CASAROLI, D.; CANEDO, S. C.; BARBOSA, K. A. Avaliação de métodos para superação de dormência na germinação de Ormosia arborea (Vell.) Harms. Revista Biotemas, Florianópolis, v. 24, n. 4, p.25-29, 2011.

VIGGIANO, J. R. Influência do teor de umidade, tipo de embalagem e ambiente de armazenamento na conservação de sementes de mamão (Carica papaya L.). 1999. 67 f. Dissertação (Mestrado em Produção Vegetal) - Universidade Estadual do Norte Fluminense, Campos dos Goytacazes, 1999.

ZAIDAN, L. B. P.; BARBEDO, C. J. Quebra de dormência em sementes. In: FERREIRA, A. G.; BORGHETTI, F. (orgs). Germinação: do básico ao aplicado. Porto Alegre: Artmed, 2004. cap. 8, p. 135-146. 